Review article

\title{
Intrinsic determinants and predictors of superovulatory yields in sheep: Circulating concentrations of reproductive hormones, ovarian status, and antral follicular blood flow
}

\author{
Pawel M. Bartlewski ${ }^{\text {a,* }}$, Patricia Seaton ${ }^{\mathrm{a}}$, Maria Emilia Franco Oliveira ${ }^{\mathrm{b}}$, \\ Rami T. Kridli ${ }^{\mathrm{a}, \mathrm{c}}$, Maciej Murawski ${ }^{\mathrm{d}}$, Tomasz Schwarz ${ }^{\mathrm{e}}$ \\ ${ }^{a}$ Department of Biomedical Sciences, Ontario Veterinary College, University of Guelph, Guelph, Ontario, Canada \\ ${ }^{\mathrm{b}}$ Department of Preventative Veterinary Medicine and Animal Reproduction, College of Agricultural and Veterinary Sciences, \\ São Paulo State University, Jaboticabal, São Paulo, Brazil \\ ${ }^{\mathrm{c}}$ Department of Animal Production, Jordan University of Science and Technology, Irbid, Jordan \\ d Department of Animal Biotechnology, Agricultural University of Kraków, Cracow, Poland \\ e Institute of Animal Sciences, Agricultural University of Kraków, Cracow, Poland
}

\section{A R T I C L E I N F O}

\section{Article history:}

Received 15 September 2015

Received in revised form 29 December 2015

Accepted 14 March 2016

\section{Keywords:}

Ewe

Superovulation

Ovarian follicles

Blood flow

Steroids

Gonadotropins

\begin{abstract}
A B S T R A C T
Hormonal ovarian superstimulation has contributed to small ruminant reproduction around the world, impacting genetic improvement and zoosanitary programs, contributing to the conservation of endangered species, and supporting other related biotechnologies. Advanced knowledge surrounding the superovulatory treatments in sheep has resulted in enhanced control of influencing factors and improved the protocols currently used. However, in spite of minimization of some adverse factors, superovulatory responses in ewes still remain variable, preventing the more widespread use of superovulation in commercial embryo transfer programs and reproductive research in this species. Recent evidence demonstrates that changes in antral follicular populations and blood supply, and circulating concentrations of certain reproductive hormones determined at the specific time points just before or during the superovulatory treatment are associated with superovulation success in ewes. This review attempts to compile the data from available literature to identify ovarian and hormonal determinants of the superovulatory outcome in ewes, which can be used to substantially improve the existing protocols and to reduce the extra cost and unnecessary stress imposed on poorly responding animals. An overview of most commonly used and some recently developed, FSH-based ovarian stimulation protocols is given at the outset to highlight variation in the frequency and timing of gonadotropin injections, estrus synchronization methods, and follicular wave synchronization and/or ovulation induction techniques during the superovulatory treatments in ewes.
\end{abstract}

(c) 2016 Elsevier Inc. All rights reserved.

\section{General introduction and overview of superovulatory protocols}

Assisted reproductive technologies (ARTs) are widely used in agricultural industry to improve livestock genetics

\footnotetext{
* Corresponding author. Tel.: 519-824-4120x53330; fax: 519-767-1450 E-mail address: pmbart@uoguelph.ca (P.M. Bartlewski).
}

and boost reproductive efficiency of individual animals [1-4]. Nearly all technologies related to embryo production and manipulation in domestic ruminants have been developed in sheep and subsequently transferred to other livestock species $[5,6]$. In sheep, hormonal ovarian stimulation is mainly used in multiple ovulation and embryo transfer (MOET) programs [7]. However, considerable variations in superovulatory responses continue to limit the application of superovulation, especially in commercial 
settings $[8,9]$. The outcomes of superovulatory treatments are highly variable as ovarian responses (Fig. 1) and embryo yields are dependent on several intrinsic and extrinsic factors including, but not limited to, the breed, age, flock management, gonadotropin preparations and doses used, type of insemination, and the interval between successive treatments [10-12]. The superovulatory outcomes are strongly influenced by the reproductive status and history of ewes as well as season and photoperiod/melatonin secretion [13-18]. All these factors can affect embryo yields and quality in breeds maintained in temperate climates; under tropical and subtropical conditions, sheep undergoing ovarian stimulation are somewhat less sensitive to photoperiodic changes [4]. Although the relationship has yet to be fully corroborated, insufficient nutrition may also impinge on embryo output by compromising follicle/ oocyte competence [19], luteal function [20], and/or early embryonic development [21-23].

Despite an increased control of extrinsic factors influencing the superovulatory outcome, ovarian responses in hormonally superstimulated sheep remain variable, suggesting that the primary causes of this variability are related mainly to intrinsic factors. One of the main inherent factors linked to variability in superovulatory yields is genotype. Prolific breeds generally show enhanced superovulatory responses, with greater numbers of transferable embryos than less prolific genotypes [24,25]. Sheep with a heterozygous inactivating mutation in the bone morphogenetic protein 15 (BMP15) gene exhibit significantly greater ovulation rates during either a natural estrous cycle or after the superovulatory treatment [24]. The BMP15 protein is a member of the transforming growth factor $\beta$ superfamily. It is a paracrine signaling molecule involved in oocyte maturation and follicular development [25]. In more than $75 \%$ of ewes actively immunized with a BMP15-keyhole limpet hemocyanin peptide in an oil-based adjuvant, given to completely neutralize BMP15 bioactivity, there was no superovulatory response to exogenous gonadotropins [26]. Premature luteinization of antral follicles during the hormonal ovarian superstimulation appeared to be the main reason for this suppression [26]. Moreover, prolific strains of sheep are more likely to be affected by a possible ovulatory threshold, which has been proposed to influence fertilization rates in superovulated sheep; a study conducted in Lacaune ewes reported a significant decrease in fertilization and transferable embryo rates in animals with more than 30 ovulations [10].

In addition to genetics, the age of animals also affects the superovulatory outcome in sheep [27], with the maximal embryo outputs typically occurring at or around 6 years of age [28,29]. Owing to the diminished follicular sensitivity to gonadotropins, induction of multiple ovulations in prepubertal females is significantly less successful compared with that in sexually mature donor ewes [30]. However, the genetic predisposition and age are not the only intrinsic factors that can modify the superovulatory
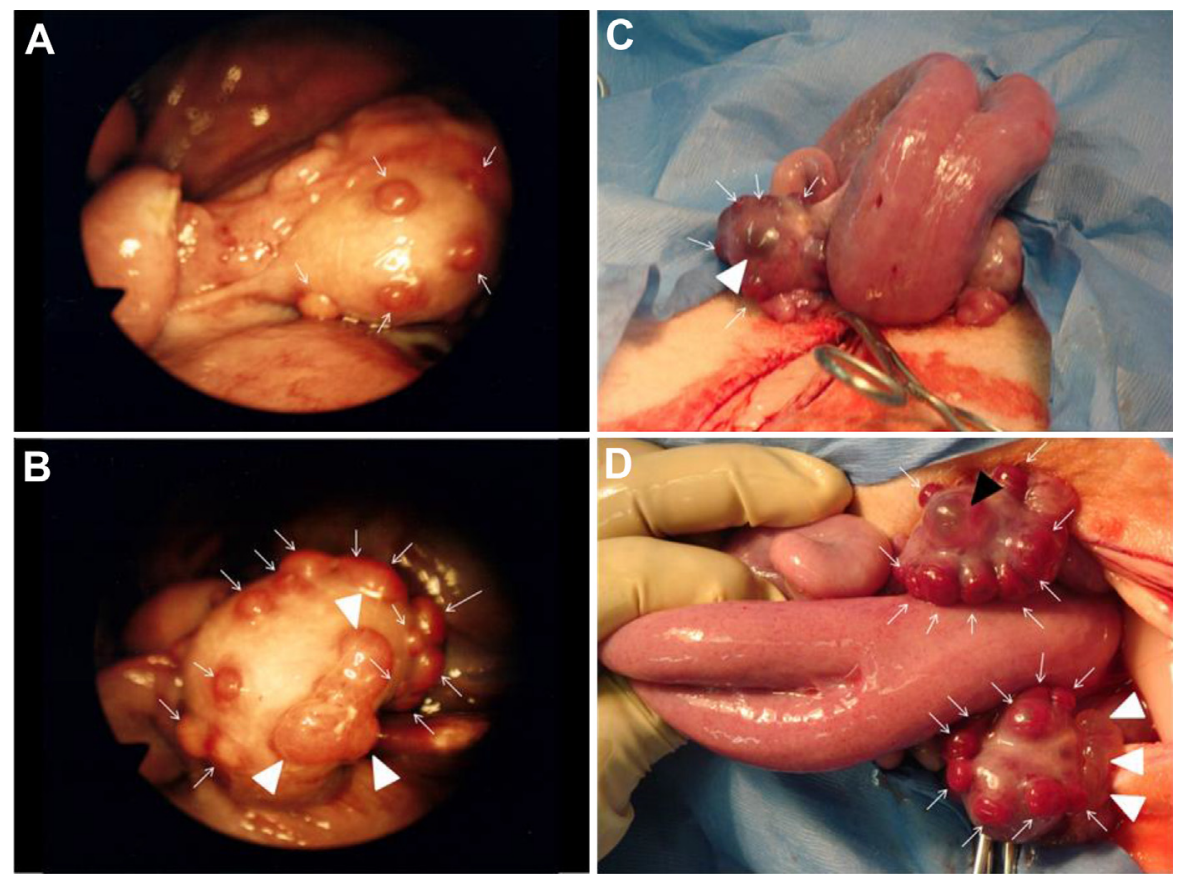

Fig. 1. Pictures of ovaries in superovulated ewes of the Olkuska breed (highly prolific genotype) obtained just before laparoscopic embryo flush (A and B) and in Rideau Arcott sheep (moderately prolific strain) at the time of laparotomy after the superovulatory treatment (C and D). Please note a relatively small size of corpora lutea (white arrows) in prolific Olkuska ewes due to ovulation of smaller antral follicles compared with Rideau Arcott sheep. A and C depict ovaries in poorly responding individuals, whereas (B and D) in well-responding ewes. The ewes were age and weight matched, and multiparous animals superovulated in the 4-day ovine FSH regimen with declining gonadotropin doses (Olkuska breed) or the 3-day porcine FSH protocol (Rideau Arcott). At the time of embryo recovery, unovulated cystic-like follicles could be observed (white arrowheads), some of them partially luteinized (black arrowhead), in animals of both genotypes. 
response. A number of hormonal influences and ovarian status may both alter the ovarian sensitivity to gonadotropic signals, ovulatory responses, and the quality and numbers of released oocytes and resultant embryos. Reduced fertilization rates after superovulation may also be caused by sperm transport disturbances after natural mating of donor animals [31]. After copulation in cows, spermatozoa locate at the uterotubal junctions and the initial portion of the isthmus establishing a sperm reservoir [31]. In superovulated animals, however, the sperm reservoirs appear to be unilateral or absent, indicating profound abnormalities in the uterine and/or oviductal sperm transport [31]. Laparoscopic intrauterine insemination has been shown to improve fertilization rates in superovulated ewes [3]. Large-scale MOET programs have achieved fertilization rates of $91.9 \%$ and $86.4 \%$ with fresh and frozen semen, respectively, deposited using laparoscopic technique [32].

Current superovulatory protocols used in small ruminants (Figs. 2-6; [7,9,33-38]) usually entail treatments with progesterone or synthetic progestin to synchronize estrus and ovulations after the superovulatory regimen, combined with an application of exogenous homospecific or heterospecific gonadotropins to induce synchronous growth of multiple antral follicles (started 2-3 days before the end of progestagen priming), artificial insemination and/or (hand)mating, and subsequent surgical embryo collection from the reproductive tract of donor animals. Both the short- (5-7 days) and long-term (12-14 days) progesterone treatments can effectively be used during the superovulatory protocols [37]. It is feasible to produce multiple embryos using the gonadotropin stimulation initiated during the normal luteal phase of the estrous cycle, without the concurrent administration of progestinreleasing vaginal pessaries; in this approach, gonadotropin administration usually commences shortly after ovulation (approximately 3-4 days after the onset estrus) and a luteolytic dose of a prostaglandin analogue is given just before the end of the 3- to 4-day superovulatory treatment [32,39]. Laparoscopic embryo recovery is possible, but significantly more cumbersome and hence less practical than laparotomies [35]. Transcervical embryo flushing in ewes is still at the experimental stage [35].

The first widely used gonadotropin preparation for superovulation in domestic ruminants was pregnant mare serum gonadotropin (now called eCG [1]). This hormone has a long half-life of approximately 72 hours in vivo and therefore is given as a single intramuscular injection 2 to 3 days before progestagen removal [1]. Its prolonged action is frequently associated with overstimulation of the ovaries, which increases the incidence of unovulated antral follicles (follicular cysts) and estradiol overproduction [40]. Elevated estrogen concentrations are believed to alter gamete and early embryo transport through the genital tract, and thereby decrease the embryo recovery rate $[40,41]$.

FSH is currently a primary choice for hormonal ovarian superstimulation. FSH given at frequent, supraphysiological doses interacts with the somatic and germinal compartments in the ovary to induce and extend the period of growth and to prevent early atresia of multiple antral follicles [5]. Total exogenous FSH doses of 176 to $256 \mathrm{mg}$ have been used for superovulation in sheep [33-37]. Peaks of circulating concentrations of porcine FSH ( $\mathrm{pFSH}$ ) during the 3-day superovulatory regimen in ewes reached 4 to $6 \mathrm{ng} /$ $\mathrm{mL}$, which is 2 to 3 times higher than mean systemic levels

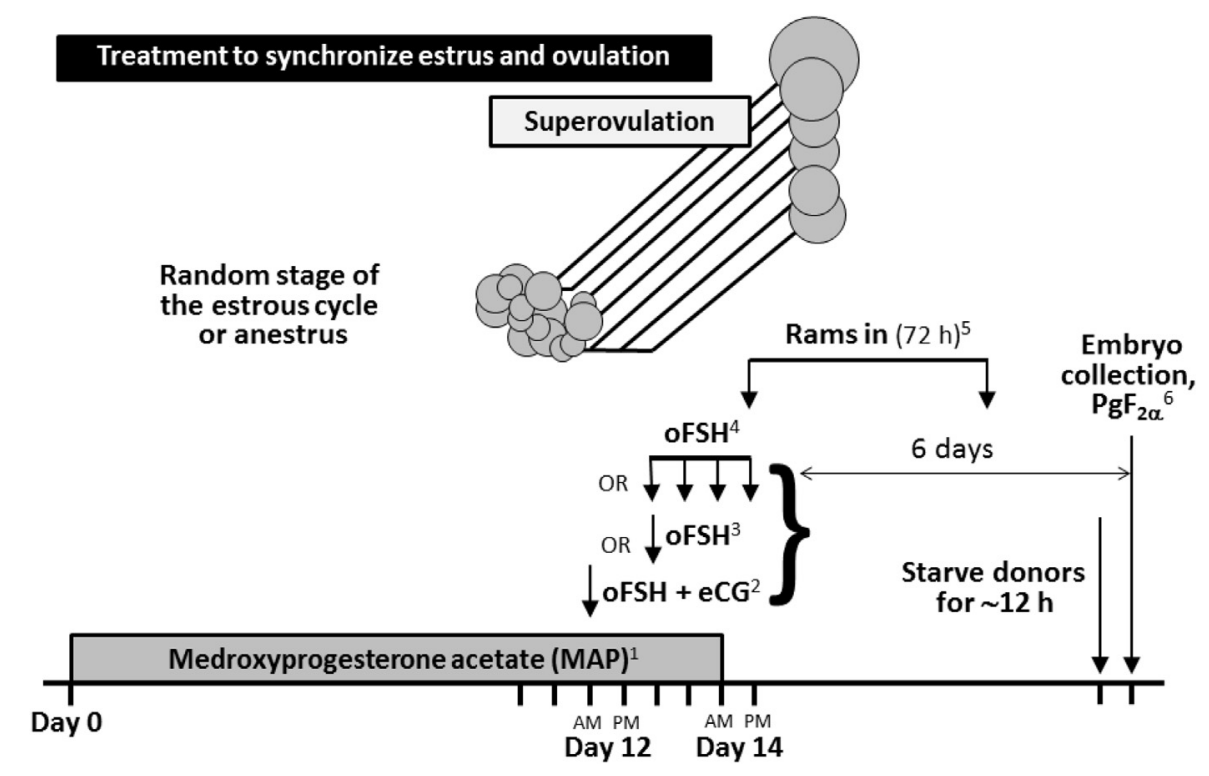

Fig. 2. Simplified superovulatory protocols using ovine FSH originally tested in Corriedale ewes [33]. ${ }^{1}$ Ewes received intravaginal progestagen-soaked sponges that were left in place for 14 days. ${ }^{2}$ Subsequently, ewes were treated with $176 \mathrm{NIH-FSH}-\mathrm{S} 1$ units of oFSH $+500 \mathrm{IU}$ eCG given as a single intramuscular (i.m.) injection in saline 48 hours before sponge withdrawal ${ }^{3}$ as a single i.m. injection of oFSH in a polyvinylpyrrolidone 24 hours before sponge removal ${ }^{4}$ or as four equal doses (i.m., dissolved in saline) administered every 12 hours from 24 hours before to 12 hours after sponge removal. ${ }^{5}$ Animals were bred naturally after the estrus detection. ${ }^{6}$ Embryos were recovered on Day 6 after estrus. 
Treatments to induce estrus and synchronize ovulation

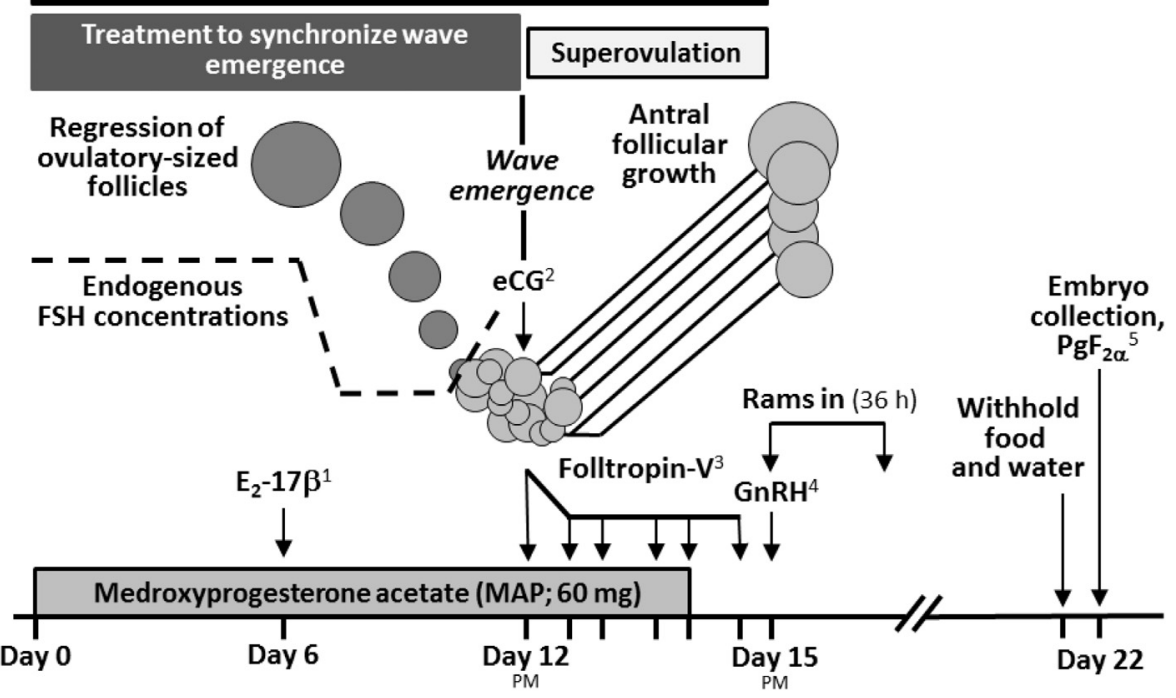

Fig. 3. A schematic of the superovulatory protocol including a suppression and resynchronization of follicle wave emergence with a medroxyprogesterone acetate (MAP)/estradiol $17 \beta\left(E_{2}-17 \beta\right)$ pretreatment of anestrous ewes [9,34]. ${ }^{1} 350 \mu \mathrm{g}$ of $\mathrm{E}_{2}-17 \beta$ in $1 \mathrm{~mL}$ of sesame oil i.m.; ${ }^{2,3}(1 \times 2.5 \mathrm{~mL}$ of Folltropin-V [porcine $\mathrm{FSH}]+500 \mathrm{IU} \mathrm{eCG})+5 \times 1.25 \mathrm{~mL}$ of Folltropin-V intramuscularly (i.m.); ${ }^{4}$ Cystorelin (50 $\mu \mathrm{g}$ i.m.); ${ }^{5}$ luteolytic dose of a PgF $2 \alpha$ analogue (Lutalyse, $10 \mathrm{mg}$ i.m.) given only to animals in which the difference between the number of corpora lutea and collected embryos exceeded three (in two of four ewes not receiving Lutalyse, healthy twins were born approximately 5 months later, unpublished observation).

of endogenous FSH observed during that period [34]. Pharmacologic doses of FSH are superior to eCG in terms of ovulation and fertilization rates as well as the number and quality of transferable embryos produced [1]. Commercially available ovine FSH (oFSH) or pFSH extracts have a relatively short half-life and are, therefore, administered as six or eight injections at $\sim 12$-h intervals, beginning 2 to 3 days before progestagen removal [1]. Decreasing doses of FSH are frequently used as they more closely mimic the endocrine changes in pituitary secretion during the follicular phase of nonstimulated estrous cycles, and tend to increase mean ovulation rates and numbers of recovered viable embryos [42]. During the mid 1980s, pFSH preparations had a highly variable $\mathrm{LH}$ content, with a higher $\mathrm{LH}$ concentration hindering ovarian responses, fertilization rates, and embryo quality in ruminant species $[43,44]$. Since the early 2000s, purified oFSH and pFSH have been available, although a minimal $\mathrm{LH}$ content in these

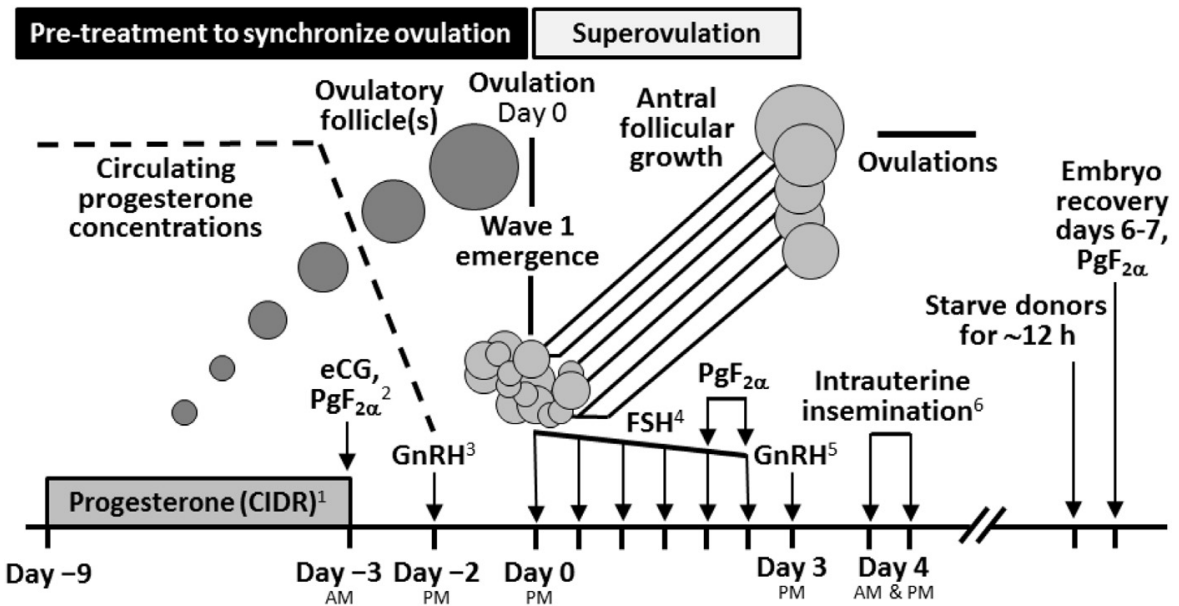

Fig. 4. Schematic representation of the "Day 0 superovulatory protocol" for sheep and goats, with the gonadotropic superstimulation initiated at the time of follicular wave emergence after ovulation. Pretreatment was performed to synchronize ovulation and wave emergence; FSH administration began 72 to 84 hours after vaginal progesterone device withdrawal [35]. ${ }^{1-3}$ Synchronization of ovulation was performed to begin superstimulation at or around emergence of Wave 1 of the estrous cycle (Day 0 of the protocol). ${ }^{4}$ Six declining intramuscular (i.m.) doses of porcine or ovine FSH were given. The primary purpose of this protocol is to ensure a homogeneous pool of small, gonadotropin-responsive follicles, which enhances the superovulatory response and reduces the incidence of anovulatory follicles. ${ }^{5,6}$ In addition, the rate of fertilization failure has been reduced by using GnRH in conjunction with intrauterine artificial insemination. 


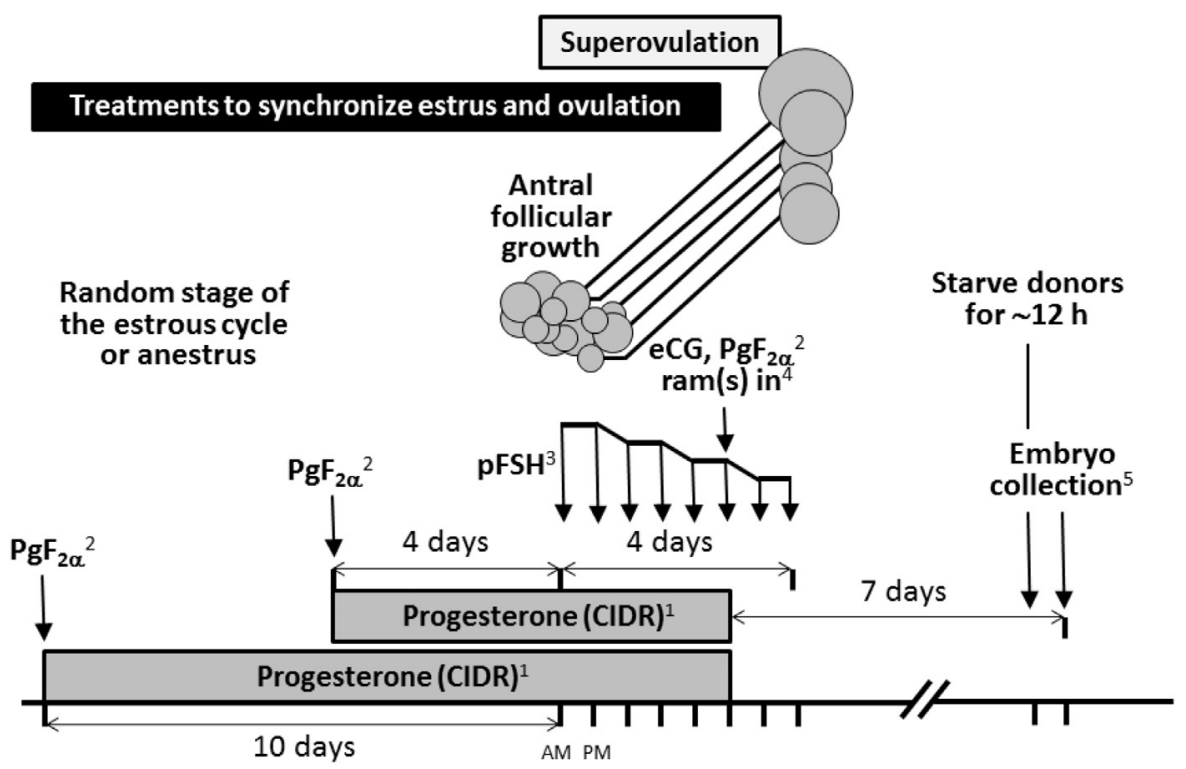

Fig. 5. ${ }^{1}$ Ewes were subjected to a short- (Days 0-6, 7 days) or a long-term (Days 0-12; 13 days), progesterone-based protocol (controlled internal drug release [CIDR]) to synchronize estrus and ovulations after superovulatory regimen. ${ }^{2}$ Animals received two injections of $37.5 \mu \mathrm{g}$ of D-cloprostenol intramuscularly (i.m.; prostaglandin $\mathrm{F}_{2 \alpha}$ analogue) on Day 0 and at CIDR removal. ${ }^{3}$ The superovulatory regimen consisted of eight i.m. injections of Folltropin-V administrated twice daily $(40,40,30,30,20,20,10$, and $10 \mathrm{mg}) .{ }^{4} \mathrm{~A}$ single i.m. dose of $300 \mathrm{IU}$ of eCG was given at the time of CIDR withdrawal. ${ }^{5}$ Subsequently, ewes were bred by a fertile $\operatorname{ram}(\mathrm{s})$ and embryos were recovered surgically 7 days later [37]. pFSH, porcine FSH.

preparations remains necessary for optimal ovulatory responses [42]. Interestingly, a study of hormonal potency of commercial pFSH preparations using both FSH immunoassays and bioassays revealed that various products and batches differed in their FSH bioactivity but not the immunoactive FSH levels [45]. This lack of correlation between bioactivity and immunoactivity of commercial FSH products led the authors to suggest that varying FSH bioactivity might be a cause of the variability observed during superovulatory treatments [45]. However, in a more

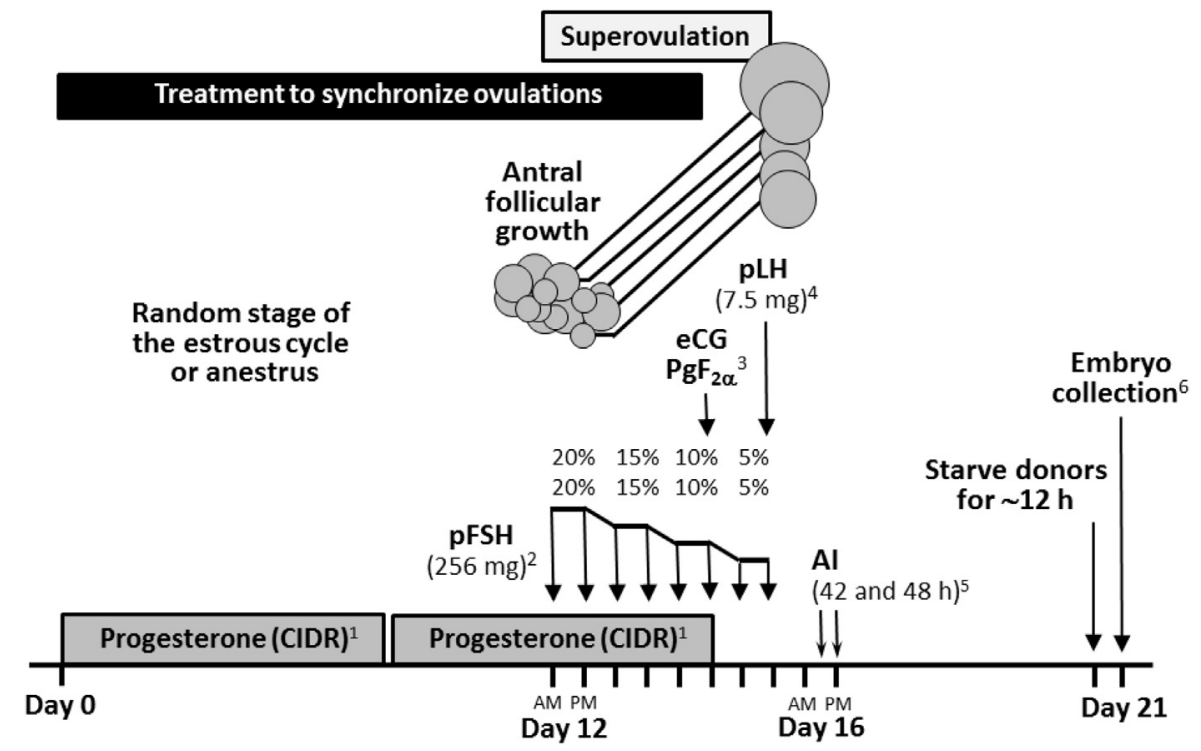

Fig. 6. The "supplementary LH" superovulation protocol [36]. ${ }^{1}$ On Day 0, a controlled internal drug release [CIDR] device was inserted, and it was replaced with a new one 7 days later, at which time $37.5 \mu \mathrm{g}$ of D-cloprostenol i.m. (prostaglandin $\mathrm{F}_{2 \alpha}$ analogue) was administered. ${ }^{2}$ On Day 12 , a superovulatory pFSH treatment (a total of $256 \mathrm{mg}$ in declining doses) consisting of eight consecutive injections given 12 hours apart commenced. ${ }^{3}$ On Day 14 , the CIDR was removed, and 200 IU of eCG and $37.5 \mu \mathrm{g}$ of D-cloprostenol administered. ${ }^{4}$ On Day 15, or 24 hours after CIDR removal, the ewes were treated with $7.5 \mathrm{mg}$ of pLH (Lutropin-V, Bioniche Animal Health, Belleville, ON, Canada). ${ }^{5}$ Artificial inseminations (AIs) were performed 42 and 48 hours after CIDR withdrawal. The ovarian structures were assessed by laparoscopy immediately before each AI and 5 days later (Day 21). ${ }^{6}$ Embryos were collected surgically. pFSH, porcine FSH. 
recent ovine study [9], separate vials and batches of pFSH preparations were pooled to prepare sufficient quantities of the gonadotropin to treat all animals (to avoid the potential effects of variability in drug biopotency); this did not prevent significant individual variations in the ovulation rate and embryo yields suggesting that possible differences in FSH bioactivity of commercial products are hardly the sole reason for unpredictable superovulatory responses in ewes. After superovulatory FSH treatments, the preovulatory LH surge may be synchronized by the administration of exogenous GnRH, given 32 to 36 hours after the withdrawal of the progestagen/progesterone source, inducing ovulations 20 to 28 hours later [7,46].

Recent investigations into ovarian and hormonal predictors of superovulatory yields in ewes offer a few potential advantages to MOET programs. This review attempts to highlight these advancements in ovine superovulation and identify specific parameters that can be used to reduce variability among superovulated ewes. Knowledge surrounding the predictors and determinants of superovulation in sheep will help establish the selection criteria for suitable donors and will also serve to reduce unnecessary economic cost and animal stress endured in the treatment of poorly responding females undergoing hormonal ovarian superstimulation. Better understanding and subsequent control of these indicators may aid in the development of an optimal superovulatory protocol(s) that would ultimately produce consistent results in various individuals, breeds, and ruminant species.

\section{Hormonal indicators and determinants of superovulatory outcomes in ewes}

Circulating hormones measured just before and during superovulation in sheep can potentially provide an indication of the anticipated superovulatory response. Numerous studies have examined hormone concentrations at the outset and during the superovulatory protocol in an attempt to identify the most responsive females. Below is a summary of the major findings.

\subsection{Inhibin $A$ and estrogens}

The success of a superovulatory program primarily depends on the presence of a large pool of gonadotropinresponsive ovarian antral follicles at the start of the treatment. Growth of these follicles is regulated by numerous factors $[47,48]$. In the follicular phase before ovulation, healthy (nonatretic) ovarian antral follicles secrete inhibin A, which promotes granulosa and theca cell differentiation and steroidogenic activity [49]. In small ruminants, inhibin $A$ is highly associated with estrogen secretion by large antral follicles [50]. Therefore, inhibin A and follicular estradiol have both been proposed as potential hormonal predictors of the superovulatory outcome in sheep and goats [51,52]. A strong positive correlation exists between plasma inhibin concentrations during superovulation and the number of corpora lutea and the total number of recovered (viable and degenerated) embryos in ewes superovulated during the breeding season [51]. Inhibin A is thought to play a role in oocyte development [48,52-54], hence its secretion may be indicative of the antral follicle population capable of releasing oocytes with high developmental competence [51]. In contrast to the positive association between inhibin $A$ secretion and the superovulatory outcome in cycling sheep and goats, Bartlewski et al. [8] and Fuerst et al. [55] reported that elevated serum estrogen concentrations at the beginning of superovulatory treatment were negatively correlated with the number of transferrable quality embryos and overall embryo viability in anestrous ewes. This may be due to increased recruitment and ovulation of large numbers of immature antral follicles containing nonviable oocytes [55] or direct detrimental effects of elevated estrogen levels on growth and maturation of follicles and/or oocytes $[8,56]$ in seasonally anovular ewes. Regardless of these opposing findings in cycling and anestrous ewes, it seems that inhibin A and follicular estrogens are good candidate indicators of the superovulatory responses in ruminants.

\subsection{Luteinizing hormone}

Reported viable embryo production after superovulation varies greatly in sheep $[1,3,7,11]$. The ovarian and endocrine changes that occur after superovulatory treatments potentiate a decrease in the number and quality of retrieved embryos, which may be attributed to abnormalities in follicular developmental and fertilization processes [56-58]. Improved purification of FSH preparations has provided an initial step in minimizing undesirable superovulatory side effects by reducing LH content of both gonadotropins and the resulting prematurely ovulated or anovular and/or luteinized follicles [11]. In spite of these improvements, variability in the preovulatory mode of $\mathrm{LH}$ secretion and its impact on the ovulation rate and oocyte competence in superovulated sheep persists.

The LH surge triggers morphologic and endocrine changes in the developing follicle and oocyte [3]. In the 24 hours after an LH discharge, the oocyte undergoes final maturation to achieve full "fertilizability." In superovulated animals, greater variation in the rate of oocyte maturation has been observed, frequently resulting in the retrieval of unfertilized oocytes [3]. Timing of the LH surge appears to be affected by season, with an earlier onset of the LH discharge observed in ewes superovulated in the breeding season as compared to those in seasonal anestrus [16]. Variation in LH timing may also be a result of supraphysiological levels of exogenous FSH; studies in nonsuperovulated sheep receiving progestagen to synchronize estrus and ovulations showed a lower variation in the time of onset of the preovulatory LH surge in comparison to superovulated sheep [56-61]. It has also been suggested that supraphysiological doses of FSH may somehow interfere with the delicate LH-driven processes required for normal oocyte maturation, specifically the preovulatory follicular steroidogenesis, the necessary sequence of cytoplasmic changes and/or alterations in oocyte protein synthesis [36,57]. However, optimal levels of FSH exposure may have a positive influence on oocyte quality because in vitro-fertilized oocytes collected from FSH-stimulated ewes have been observed to possess a greater cleavage rate than those from nonstimulated animals [62]. 
The out-of-sync patterns of the preovulatory LH surge have dissimilar effects on superovulatory yields. A significant delay or truncation in the preovulatory LH surge may negatively affect the ovulatory response by stunting the terminal maturation of ovulatory follicles or preventing ovulation from occurring $[63,64]$. A lack of LH surge synchrony may then extend onto the interval between ovulation and fertilization, thus influencing normal progression of the ensuing time-sensitive embryo development stages [61]. Surges triggered earlier and lasting longer are related to a higher number of degenerated embryos and a lower embryo viability rate, whereas shorter surges initiated later are associated with improved fertilization and embryo viability rates [61]. A later LH surge is believed to allow for prolonged follicular maturation, essential for achieving full developmental competence of oocytes [65]; this timing effect is further supported by studies reporting increases in both the number of ovulations and viable embryos after a delay in follicular exposure to LH after superovulation [66]. Therefore, it is logical to assume that manipulations of timing and duration of the preovulatory LH surge might affect transferrable embryo yields in superovulated ewes.

Fertilization failure after superovulation may in fact be reduced by improving the synchrony between ovulation and insemination procedures [33]. Ovulation is commonly synchronized with the administration of GnRH, but the use of $\mathrm{GnRH}$ for this purpose has been somewhat controversial. Contradicting reports of an increased embryo yield after a dose of GnRH [67], and the potential for a second LH surge associated with decreased embryo production [1] are found in the literature. A recent study reported a significant improvement in fertilization rate (84\%-93\%) and number of transferable embryos collected per donor (approximately six-eight) in ewes receiving GnRH approximately 24 hours after controlled internal drug release withdrawal compared with donor animals not receiving GnRH [68]. Supplemental pLH (7.5 mg/ewe intramuscularly) given concurrently with the last pFSH dose to Santa Inês ewes increased the proportion of donors with $\geq 11$ ovulations and ovulating before 42 hours after the controlled internal drug release removal, but the embryo production in LH-treated animals did not differ from that in their counterparts that did not receive Lutropin injections [36].

\subsection{Progestin priming and luteal progesterone secretion}

Exogenous progestins may alter the patterns of antral follicular growth $[68,69]$ and luteal status at the time of progestagen/natural progesterone administration modifies their effects [12]. Insertion of the progestagen source at various stages of the estrous cycles in ewes would result in exposure to varying levels of gestagens depending on the presence or absence of progesterone-releasing CL. The growth rate and lifespan of large antral follicles is shortened when progestagen is administered in the presence of a functional CL and is lengthened if the treatment commences in the absence of luteal structures [70-72]. Gonzalez-Bulnes et al. [12] have shown that a longer (12- to 14-day) synchronization treatment with two consecutive progestagen sponges improves the superovulatory response; however, differences between ewes still exist depending on the phase of the cycle in which the progestagen source is first inserted.

Varying durations of progesterone before treatment (514 days) did not significantly affect the proportion of responding animals, the mean number of $\mathrm{CL}$, or the mean number of recovered and transferable embryos per donor in ewes under subtropical [37] and tropical [68] conditions. To the best of our knowledge, no attempt has been made to date to compare the outcomes of the short- and long-term synchronization protocols in cycling and seasonally anestrous ewes in temperate climates characterized by a more pronounced annual reproductive seasonality.

After the superovulatory treatment with pFSH, serum progesterone concentrations are not directly related to the number of luteal structures present [55]. There were no correlations between serum progesterone concentration and ovulatory responses in anestrous ewes superovulated in a multiple-dose pFSH regimen [55]. This is also in agreement with an earlier study by Grazul-Bilska et al. [73] in which serum progesterone levels on Day 5 after estrus did not vary significantly between superovulated and normally cycling Western range-type ewes; a lack of difference was due mainly to highly variable progesterone concentrations in superovulated animals. Hence, serum progesterone levels appear to be a poor predictor of the number of ovulations and/or luteinized unovulated follicles. Supraphysiological progesterone concentrations before embryo recovery do not seem to be related to the numbers of resultant embryos nor do they affect embryo quality in ewes [55].

\subsection{Endogenous and exogenous FSH concentrations}

Bartlewski et al. [9] examined the relevance of circulating FSH concentrations to superovulatory performance, which revealed that changes in endogenous FSH concentrations during superovulation might contribute to the variability in superovulatory responses in ewes (Fig. 7). Intriguing observations and subsequent correlations with superovulatory outcome were made during the progestagen priming and superovulatory treatments in anestrous ewes. A single injection of $E_{2}-17 \beta$ on Day 6 of the 14-day progestagen pretreatment (Veramix; medroxyprogesterone acetate, $60 \mathrm{mg}$ ) resulted in truncation of periodic peaks in mean FSH concentrations, which prevented the entry of ovarian antral follicles into follicular waves for 4 to 5 days. Interestingly, the reduction in FSH secretion after an $E_{2}-17 \beta$ injection was not observed to affect the number of small and medium-sized ovarian follicles in ewes; the latter is in accordance with a study conducted in cycling ewes treated with a subcutaneous implant releasing supraphysiological concentrations of $E_{2}-17 \beta$ between Days 4 and 14 after ovulation [74]. On the basis of these findings, it appears that periodic increases in endogenous FSH concentrations that stimulate follicle wave emergence are not essential for maintaining the pool of small antral follicles $(2-3 \mathrm{~mm}$ in size) or their growth to $4 \mathrm{~mm}$ (medium-sized follicles) in cyclic and seasonally anovular ewes.

A partial suppression of oFSH release by $E_{2}-17 \beta$ in anestrous ewes did extend into a period of ovarian stimulation with pFSH (i.e., 6-9 days after $E_{2}-17 \beta$ injection [9]). 

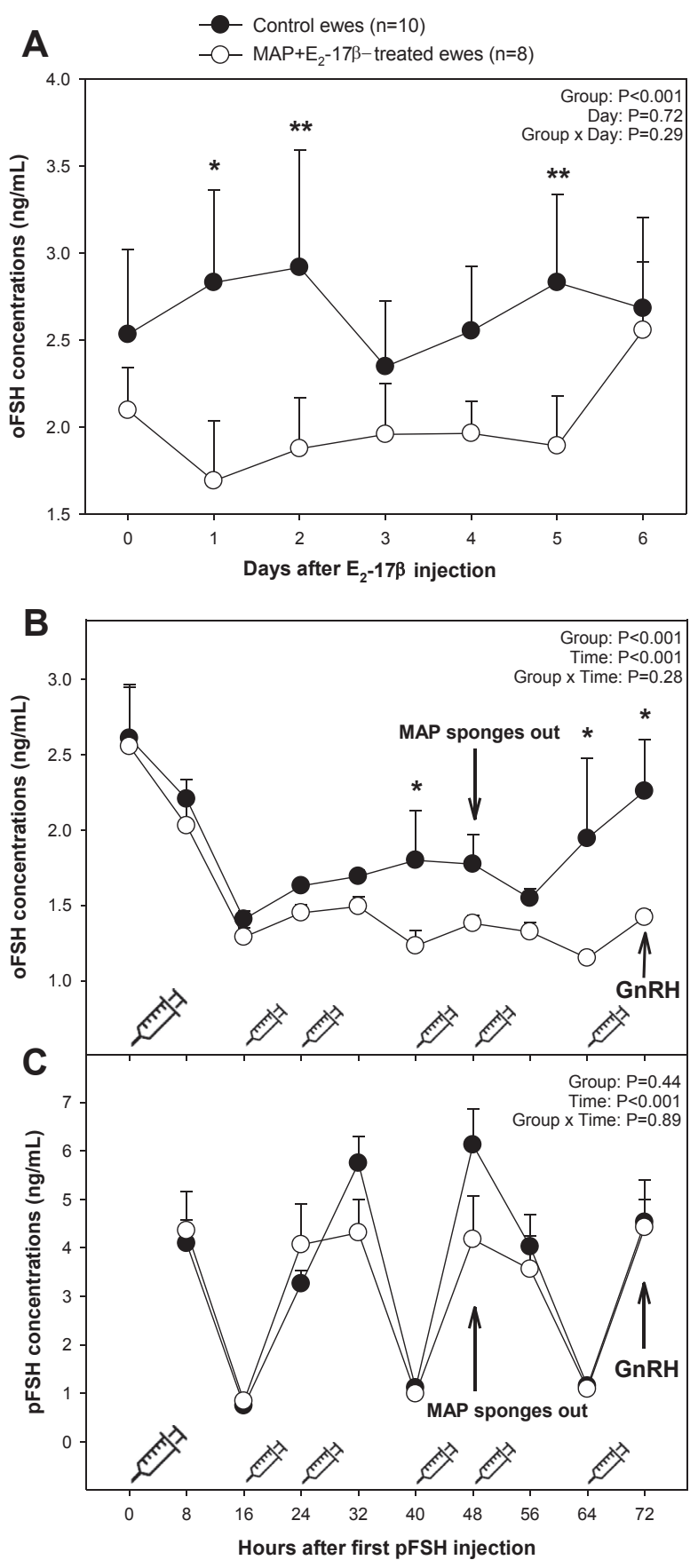

Fig. 7. Mean ( \pm standard error of the mean) serum concentrations of ovine $\mathrm{FSH}$ (oFSH; A and B) and porcine FSH (pFSH; C) in blood samples collected for 6 days from MAP-treated ewes with or without (control animals) a single estradiol-17 $\beta$ ( $\left.E_{2}-17 \beta\right)$ injection (350 $\mu \mathrm{g}$ intramuscularly [i.m.]) given to synchronize follicle wave emergence $(A)$ and every 8 hours during the ensuing superovulatory treatment. Syringe symbols along the $\mathrm{X}$-axis indicate the times of Folltropin- $V$ injections (B and C) [9,34]. A single i.m. injection of $500 \mathrm{IU}$ of eCG was given concurrently with the first pFSH dose (Time 0 hours, large syringe). Asterisks indicate significant difference between groups.

During that period, serum oFSH concentrations appeared to be an important indicator of the superovulatory outcome. The circulating levels of endogenous FSH at the beginning
( 8 and 16 hours) and toward the end (56 and 64 hours after the first Folltropin-V injection) of the 3-day superovulatory treatment were positively correlated with the ovulation rate and the total number of recovered embryos [9]. In addition, the embryo viability rate (i.e., percentage of viable embryos) was strongly and positively correlated to serum oFSH concentrations at Time 0 hours and inversely related to the number of degenerating embryos. Finally, oFSH concentrations were positively correlated to numbers of degenerated embryos at Time 48 hours [9]. There were no correlations between the superovulatory responses analyzed and serum concentrations of pFSH throughout the period of ovarian stimulation [9]. Since a reduction in serum oFSH was associated with significantly less variable ovulatory responses and embryo yields, it was concluded that intrinsic variation in oFSH levels could cause variable superovulatory responses in anestrous ewes [9]. Therefore, it is attractive to speculate that suppression of endogenous FSH production might result in more uniform and predictable outcomes of superovulatory treatments in domestic animals. The specific causative mechanisms of correlations among endogenous FSH concentrations and superovulatory responses observed in anestrous ewes remain to be elucidated.

Another intriguing observation in that study was a transient reduction in endogenous FSH concentrations after the withdrawal of progestagen sponges (Fig. 7; [9]). Moreover, serum levels of pFSH failed to increase 8 hours after a Folltropin- $\mathrm{V}$ injection given at the time of progestagen sponge removal (Time 48 hours), as they did in response to previous and subsequent gonadotropin injections (Fig. 7). This is most likely due to alterations in intermediate FSH metabolism induced by a rapid change in steroid milieu [75,76]. Lower serum levels of $\mathrm{P}_{4}$ or synthetic progestin tend to increase the less acidic isoforms of FSH in circulation causing FSH to be cleared from the blood at a faster rate [77]. More importantly, however, this decline in circulating FSH concentrations may impede the terminal growth and maturation of preovulatory, gonadotropindependent follicles. On the other hand, high circulating concentrations of oFSH observed at the time of sponge withdrawal appear to have a negative impact on resultant embryo quality [9]. Moreover, acidic FSH isoforms are better facilitators of ovarian follicular development, steroidogenic activity, and oocyte maturation than the less acidic mix [78]. Future studies are required to corroborate the effects of manipulating the endogenous FSH levels and the influence of different FSH isoforms on the efficiency of superovulatory protocols in sheep.

\subsection{Anti-Müllerian hormone}

A few studies have eluded to the role of anti-Müllerian hormone (AMH; a.k.a. Müllerian inhibiting factor) as a predictor of the ovarian stimulation outcome in humans $[79,80]$, cattle [81,82], and goats [83]. AMH is a glycoprotein belonging to the transforming growth factor family [81]. It is solely secreted by follicular granulosa cells [84,85] and hence has been used as an endocrine marker of ovarian follicular reserve in several mammalian species. $\mathrm{AMH}$ concentrations are also a reliable indicator of the number of 
small gonadotropin-responsive antral follicles [82]. A strong positive correlation exists between systemic AMH concentrations at the start of the superovulatory protocol and the numbers of transferrable embryos per donor cow [82] and goat [83]. In addition, AMH levels were found to be highly variable between individual cows while showing very low variability within each animal [81]. The work of Rico et al. [81] has shown that because of its relatively low within-animal variability, AMH concentrations can be used as a marker for selecting donor cows even several months before their entry into a superovulatory program.

Up until recently, there have been no studies on the relationship of serum $\mathrm{AMH}$ concentrations and ovarian responses to gonadotropic stimulation in ewes. Lahoz et al. [86] measured AMH concentrations in prepubertal and sexually mature Rasa Aragonesa ewes that were carrying or not carrying the prolific $\operatorname{FecX}(\mathrm{R})$ allele. In addition, their aim was to establish whether or not AMH concentrations determined during a laparoscopic ovum pick-up program could be predictive of the number of ovarian follicles ( $\geq 3 \mathrm{~mm}$ ) and recovered oocytes. Similar to cattle, there was a large variability between individuals of the same age and between animals of various ages in terms of circulating AMH concentrations. There was no correlation between AMH concentrations before puberty and during adulthood, probably reflecting individual variations in follicular populations and growth dynamics. The presence of the $\operatorname{FecX}(\mathrm{R})$ allele did not affect plasma AMH levels. In adult ewes, the AMH concentrations at the beginning of the FSH treatment were strongly and positively correlated with the number of aspirated follicles at laparoscopic ovum pick-up in all animals under study, and it was possible to accurately determine AMH cutoff points for both genotypes to accurately identify high-responding ewes. This is the first report of the relationship between peripheral $\mathrm{AMH}$ concentrations and the ovarian response to FSH stimulation in ewes. Such an indicator can potentially be used to improve the efficacy of MOET programs in sheep by selecting the most valuable donor animals. These results, however, must be viewed with caution. The most recent study looking at the relationships among plasma AMH levels, ovum pick-up, and ensuing embryo production outcomes in Holstein-Friesian heifers has revealed that quantitative correlations between AMH and outcomes of an OPU-IVF program are too low to use AMH as a precise predictive parameter for OPU procedure [87], although the consistency of $\mathrm{AMH}$ measurements for predicting superovulatory success in cows is very high.

\section{Ovarian factors affecting superovulation}

\subsection{Number of small antral follicles at superovulatory outset}

It is evident from ultrasonographic and endoscopic ovarian visualization that the ovulatory response to ovarian stimulation and the total number of transferable embryos is affected by the number of small $(2-3 \mathrm{~mm})$ and large antral follicles $(\geq 6 \mathrm{~mm}$ ) present on the ovary at the beginning of the superovulatory treatment [1]. The number of small antral follicles (2-3 $\mathrm{mm}$ in diameter) at the first $\mathrm{oFSH} / \mathrm{pFSH}$ injection is representative, in most instances, of the follicular population potentially responsive to FSH and capable of growing to ostensibly ovulatory sizes. Brebion and Cognie [88] reported a positive correlation between the number of small ovarian follicles detected at the beginning of the superovulatory treatment, and the ovulation rate and viable embryo yield in sheep. However, this association is primarily dependent on the responsiveness of these follicles to exogenous gonadotropins. In a study by Bartlewski et al. [8], the numbers of small antral follicles at the beginning of the superovulatory treatment were not correlated with superovulatory responses, but the numbers of medium-sized ( $4 \mathrm{~mm}$ in diameter) antral follicles detected 12 hours after the first pFSH injection were correlated with the numbers of luteal structures and viable embryos after superovulation of anestrous ewes. Because the number of gonadotropin-responsive follicles in anestrous ewes, as indicated by the number of follicles attaining $4 \mathrm{~mm}$ in size after the first superovulatory pFSH dose, was less than the total number of small antral follicles detected at the beginning of the treatment, it is evident that in spite of the acquisition of gonadotropin receptors [44,89], only a proportion of small antral follicles might use exogenous FSH for further growth culminating in ovulation. Whether or not this phenomenon is confined to or just more pronounced in seasonally anestrous than in cycling ewes remains to be elucidated.

Gonzalez-Bulnes et al. [88] have found out that the number of antral follicles 2 to $3 \mathrm{~mm}$ in size at the first FSH dose was positively correlated with the number of follicles $\geq 4 \mathrm{~mm}$ at the time of progestin sponge withdrawal in superovulated Manchega ewes. A greater number of follicles $\geq 4 \mathrm{~mm}$ in size on the day of sponge removal was associated with an earlier onset of estrus and LH surge and a higher ovulation rate. However, the rate of embryo recovery was significantly decreased in ewes with earlier preovulatory LH peaks. Therefore, low embryo recovery rates may potentially nullify the greater number of ovulations in ewes with high numbers of small antral follicles present at the beginning of hormonal stimulation. More studies are needed to clarify these relationships in ewes.

\subsection{Follicular dominance and codominance}

According to several authors, large ovarian follicles exert a dominant effect in sheep $[50,56,90]$. The secretion of estradiol and inhibin A by large follicles provides negative feedback signals, reducing FSH availability and suppressing the growth of subordinate gonadotropin-dependent follicles [50]. Some studies suggest that several molecules modulate the theca and granulosa cell responses to low concentrations of circulating FSH [90-92]; however, evidence from sheep studies suggests that large follicles can be rescued from regression by shifting their dependence from FSH to LH [47], which is accomplished by the acquisition of $\mathrm{LH}$ receptors on granulosa cells. During the extended periods of low $\mathrm{LH}$, such as anestrus or the middle portion of the luteal phase, follicular dominance in ewes is weakened or absent [93].

A number of studies support the notion that follicular dominance has a detrimental effect on the superovulatory outcome in sheep. Several reports have shown an increase 
in the number of ovulations and embryo viability rates when superovulation is initiated in the absence of large ( $\geq 6 \mathrm{~mm}$ ) ovarian follicles [3,12,94-96]. A potential codominant effect of the 2 largest follicles (F1 and F2) has also been suggested as the physiological status of F1 and F2 at the outset of superovulatory treatment in cycling Manchega ewes (nonprolific, Mediterranean dairy breed) can affect ovulation rate and embryo recovery [97]. The presence of growing F1 follicles is negatively correlated with embryo yields and viability and regressing F2 follicles are associated with increased ovulatory responses and embryo recovery rates [97].

Despite such findings in cycling sheep, other studies have shown that during the nonbreeding season, large follicles are unable to establish inhibitory effects over smaller follicles $[8,55,94]$. An investigation into the size and physiological status of the two largest follicles (F1 and F2) detected at the onset of the FSH treatment in anestrous ewes showed no difference in superovulatory outcomes regardless of the size or developmental status of these follicles $[8,55,94]$. In a recent study conducted in cycling sheep, ovarian follicular data collected daily by transrectal ultrasonography showed no effect of the largest (dominant) or two largest (codominant) follicles on the growth of smaller follicles or the superovulatory outcome in Rideau Arcott $\times$ Polled Dorset ewes (moderately prolific breed; Bartlewski et al., unpublished). Data obtained in those studies report the absence of follicular dominance or codominance in both seasonally anestrous and cyclic ewes. Thus, the existence of follicular dominance and its possible inhibitory effects on FSH-triggered follicular emergence in sheep remains controversial owing to the inconsistencies found in the available literature [98-100].

\subsection{Corpus luteum}

Another ovarian structure of significance to sheep superovulation is the $\mathrm{CL}$. The presence or absence of luteal glands at the beginning of FSH treatment has been observed to affect the number and quality of embryos obtained from superovulated ewes [101]. Specifically, the presence of a CL at the first FSH dose during the breeding season has been shown to increase the final number of transferable embryos by decreasing their degeneration rates [101]. The lower embryonic degeneration rates are attributed to the local effects of progesterone on reducing follicular atresia and enhancing oocyte nuclear maturation $[102,103]$. Whether or not synthetic progestins and exogenous progesterone can mimic these effects of luteal progesterone in ewes differing in age and reproductive state (e.g., seasonal anestrus, breeding season, and transitional periods) remains unknown.

Ovulatory responses in superovulated ewes can be relatively easily assessed using laparoscopy or transrectal ovarian ultrasonography $[8,64,73]$. Although considered a fairly simple surgical technique, laparoscopy is nevertheless invasive and causes undue stress to donor ewes. It is also time consuming and requires specialized equipment and trained personnel to perform the procedure [32]. Unless it is coupled with the intrauterine artificial insemination [37], repeated use of this method in superovulated sheep is generally not recommended as it remains a concern for animal welfare. Because of its versatility and noninvasive character, ultrasound imaging is a method of choice for monitoring ovarian status after superovulatory treatments in ewes. Although the accurate enumeration of preovulatory follicles and CL may be difficult with ultrasonography (high numbers of antral follicles and CL decreases the accuracy of detecting individual ovarian structures), it helps identify poorly responding ewes and nonresponders.

\section{Ovarian blood flow}

Increased ovarian activity requires and stimulates greater blood flow. An increase in uterine and ovarian blood flow volume (BFV) is observed during ovarian stimulation in dairy cows $[104,105]$. Although BFV increased concurrently with follicular and luteal development, neither of the above studies managed to establish a relationship between blood flow and superovulatory outcomes in cattle. Alternatively, Witt et al. [106] monitored ovarian BFV and linked it to the effectiveness of the ovarian response to superovulation in horses. That study reported a correlation between the uterine artery pulsatility index and the number of recovered embryos in mares. No similar published reports are presently available for sheep, and it may be a useful area to explore in future studies.

In a recent study using color Doppler ovarian ultrasonography in superovulated ewes (Fig. 8), there was a positive correlation between the quantitative estimates of follicular blood flow on the final day of the 4-day superovulatory FSH treatment (declining doses) and the number of unfertilized eggs [37]. Although that study did not present a large number of significant correlations, it nonetheless provides a commercially practical tool for predicting superovulatory outcomes in ewes and evidence for the existence of antral follicular blood flow threshold that may impinge negatively on oocyte competence when surpassed during hormonal ovarian superstimulation. The sheep with the blood flow indices close to $20 \%$ (percentage of follicular blood flow area relative to the entire crosssectional area of the ovary) had ostensibly more unfertilized eggs compared with all other animals studied.

\section{Summary and conclusions}

The difficulty incurred to date in the attempt to develop a standardized superovulatory protocol to be used in MOET programs in sheep demonstrates that many intrinsic and extrinsic factors interact in an integrative manner during hormonal ovarian superstimulation. Modifications to the technical aspects, such as the synchronization and/or induction of ovulations, have significantly improved this technology in small ruminants. However, hormonal ovarian simulation invariably continues to result in profound ovarian and endocrine changes. Alterations in normal follicular development and secretory function affect oocyte maturation, ovulation, sperm transport and fertilization, and early embryonic development. Such disturbances decrease the number and viability of retrieved embryos and/or account for the highly variable responses observed 

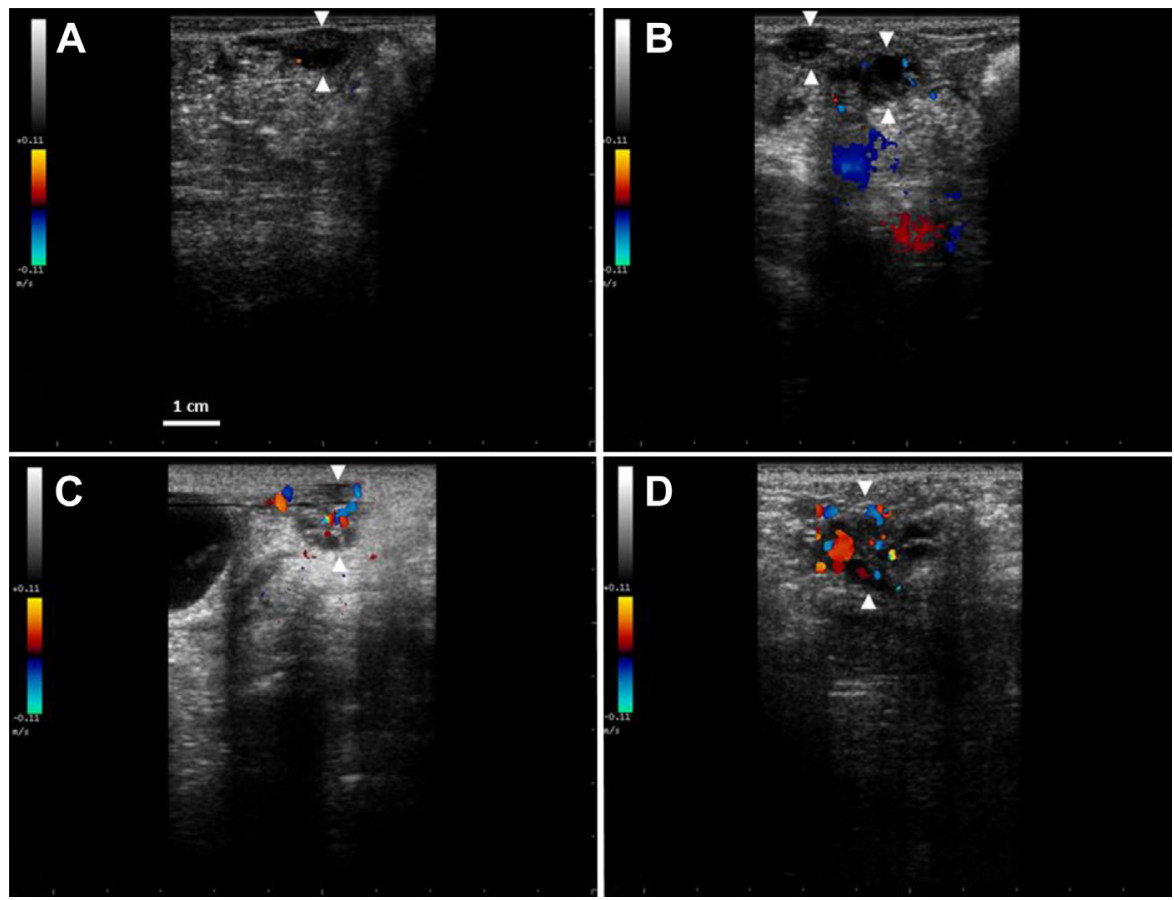

Fig. 8. Color Doppler sonograms of ovine ovaries obtained during the superovulatory porcine FSH (pFSH) treatment of anestrous Santa Inês ewes and classified arbitrarily as exhibiting nondetectable or small (A and B), moderate (C), or intense (D) blood flow [36]. White arrowheads delineate ovarian boundaries.

in ewes following superovulation. Increased knowledge of ovarian physiology, in particular of antral follicular dynamics and their relationships with superovulatory outcome, has already provided a valuable indication of the anticipated response in donor animals. However, the continued lack of consistency in superovulatory yields suggests that perhaps it is time to broaden our focus beyond the aforementioned modifications of ovarian stimulation protocols and evaluation of gonadal status.

Several physical and physiological criteria can be assessed to aid in predicting the superovulatory outcome in sheep. Those include the measurement of serum concentrations of ovarian and pituitary hormones (inhibin A, estrogen, AMH, endogenous FSH and/or LH), determination of the presence and numbers of ovarian structures (antral follicles and $\mathrm{CL}$ ), and monitoring ovarian follicular blood flow. The characterization of hormonal profiles in ewes during superovulation has the potential to identify additional endocrine indicators of superovulatory outcome that will establish reliable criteria for the selection of wellresponding donors. The subsequent control of these endocrine predictors promises to aid in the development of an optimal superovulatory treatment that produces optimal and predictable results. For example, the novel discovery of the link between reduced endogenous FSH concentrations during the gonadotropic stimulation and improved, less variable superovulatory outcome in anoestrous ewes is an intriguing relationship worthy of further investigation. Together, the measurement and control of circulating concentrations of endogenous and exogenous hormones may advance the efficacy of superovulatory protocols and related ARTs for use in multiple animal species. It is possible, however, that specific hormonal and ovarian indicators will have to be determined for different superovulatory protocols and breeds of sheep (i.e., animals varying in prolificacy), for ewes of different ages and reproductive history (i.e., maiden ewes vs. multiparous dams), for various geographic regions and seasons, and perhaps even for different kinds of progestins used in estrus synchronization regimens. Finally, color Doppler sonography has the makings of a useful practical method and research tool for detecting the hemodynamic markers of antral follicular health and oocyte quality in individual superovulated animals.

\section{Acknowledgments}

The authors' research was funded by the following agencies, institutions, or organizations: Natural Sciences and Engineering Research Council (NSERC) of Canada; Ontario Ministry of Agriculture, Food and Rural Affairs; Ontario Sheep Marketing Agency (OSMA); Department of Biomedical Sciences, Ontario Veterinary College, University of Guelph, ON, Canada; Jordan University of Science and Technology (sabbatical funding of RTK); Fundação de Amparo à Pesquisa do Estado de São Paulo (FAPESP); Polish Ministry of Science and Higher Education; and Department of Swine and Small Ruminant Breeding, Agricultural University of Kraków, Cracow, Poland.

\section{References}

[1] Cognie Y. State of the art in sheep-goat embryo transfer. Theriogenology 1999;51:105-16. 
[2] Campbell JR, Kenealy MD, Campbell KL. Animal sciences: the biology, care, and production of domestic animals. Fourth edition. New York: McGraw-Hill; 2003.

[3] Cognie Y, Baril G, Poulin N, Mermillod P. Current status of embryo technologies in sheep and goats. Theriogenology 2003;59:171-88.

[4] Amiridis GS, Cseh S. Assisted reproductive technologies in the reproductive management of small ruminants. Anim Reprod Sci 2012;130:152-61.

[5] 1998 Loi P, Ptak G, Dattena M, Ledda S, Naitana S, Cappai P. Embryo transfer and related technologies in sheep reproduction. Reprod Nutr Dev 1998;38:615-28.

[6] Betteridge KJ. A history of farm animal embryo transfer and some associated techniques. Anim Reprod Sci 2004;79:203-44.

[7] Shipley CFB, Buckrell BC, Mylne MJA, Pollard J, Hunton JR. Artificial insemination and embryo transfer in sheep. In: Youngquist RS, Threlfall WR, editors. Current therapy in large animal Theriogenology 2. Saint Louis, Mo: Saunders/Elsevier; 2007. p. 629-41.

[8] Bartlewski PM, Alexander BD, King WA. Ovarian and endocrine determinants of superovulatory responses in anoestrous ewes. Small Rumin Res 2008;75:210-6.

[9] Bartlewski PM, Alexander BD, Rawlings NC, Barrett DMW, King WA. Ovarian responses, hormonal profiles and embryo yields in anoestrous ewes superovulated with Folltropin ${ }^{\circledR}-\mathrm{V}$ after pretreatment with medroxyprogesterone acetate-releasing vaginal sponges and a single dose of oestradiol-17 $\beta$. Reprod Domest Anim 2008;43:299-307.

[10] Torres S, Cognie Y, Colas G. Transfer of superovulated sheep embryos obtained with different FSH-P. Theriogenology 1987;27:407-19.

[11] Gordon I. Controlled reproduction in sheep and goats. New York, NY: CAB International; 1997.

[12] Gonzalez-Bulnes A, Baird DT, Campbell BK, Cocero MJ, GarciaGarcia RM, Inskeep EK, et al. Multiple factors affecting the efficiency of multiple ovulation and embryo transfer in sheep and goats. Reprod Fertil Dev 2004;16:1-15.

[13] Gherardi PB, Lindsay DR. The effects of season on the ovulatory response of Merino ewes to serum from pregnant mares. J Reprod Fertil 1980;60:425-9.

[14] Lopez-Sebastian A, Cognie Y, Cocero MJ, De La Fuente J, Poulin N. Effect of season and duration of FSH treatment on embryo production in sheep. Theriogenology 1990;34:175-80.

[15] Samartzi F, Boscos C, Vainas E, Tsakalof P. Superovulatory response of Chios sheep to PMSG during spring and autumn. Anim Reprod Sci 1995;39:215-22.

[16] Mitchell LM, Dingwall WS. Season affects characteristics of the pre-ovulatory LH surge and embryo viability in superovulated ewes. Anim Reprod Sci 2002;74:163-74.

[17] Mitchell LM, Silveira M, Mylne MJ, Matthews K, Dingwall WS. Seasonal differences in lamb birthweight do not arise from inherent differences in the oocyte and/or early embryo. Reprod Fertil Dev 2002;14:207-13.

[18] Zhang L, Chai M, Tian X, Wang F, Fu Y, He C, et al. Effects of melatonin on superovulation and transgenic embryo transplantation in small-tailed han sheep (Ovis aries). Neuro Endocrinol Lett 2013;34:294-301.

[19] O'Callaghan D, Yaakub H, Hyttel P, Spicer LJ, Boland MP. Effect of nutrition and superovulation on oocyte morphology, follicular fluid composition and systemic hormone concentrations in ewes. J Reprod Fertil 2000;118:303-13.

[20] Jabbour HN, Ryan JP, Evans G, Maxwell WM. Effects of season, $\mathrm{GnRH}$, administration and lupin supplementation on the ovarian and endocrine responses of merino ewes treated with PMSG and FSH-P to induce superovulation. Reprod Fertil Dev 1991;3: 699-707.

[21] Abecia JA, Lozano JM, Forcada F, Zarazaga L. Effect of level of dietary energy and protein on embryo survival and progesterone production on day eight of pregnancy in Rasa Aragonesa ewes. Anim Reprod Sci 1997;48:209-18.

[22] Abecia JA, Forcada F, Palacín I, Sánchez-Prieto L, Sosa C, FernándezForen A, et al. Undernutrition affects embryo quality of superovulated ewes. Zygote 2013;9:1-9.

[23] Lozano JM, Lonergan P, Boland MP, O'Callaghan D. Influence of nutrition on the effectiveness of superovulation programmes in ewes: effect on oocyte quality and post-fertilization development. Reproduction 2003;125:543-53.

[24] Bindon BM, Piper LR, Cahill LP, Draincourt MA, O’Shea T. Genetic and hormonal factors affecting superovulation. Theriogenology $1986 ; 25: 53-70$.

[25] Dufour JJ, Cognie Y, Mermillod P, Mariana JC, Romain RF. Effects of the Booroola Fec gene on ovarian follicular populations in superovulated Romanov ewes pretreated with a GnRH antagonist. J Reprod Fertil 2000;118:85-94.

[26] Juengel JL, Quirke LD, Lun S, Heath DA, Johnstone PD, McNatty KP. Effects of immunizing ewes against bone morphogenetic protein 15 on their responses to exogenous gonadotrophins to induce multiple ovulations. Reproduction 2011;142:565-72.

[27] Theriez C, Desvignes A, Thimonier S. Amelioration de la prolificite chez les ovins. Bull Tech Inf Minn 1971;157:1-7.

[28] Torres S, Sevellec C. Repeated superovulation and surgical recovery of embryos in the ewe. Reprod Nutr Dev 1987;27:859-63.

[29] Driancourt MA, Fry RC, Campbell BK, McNeilly AS. Granulosa cell content and production of steroids, inhibin and follicular peptides by large follicles from a range of prolific and non-prolific breeds of sheep. J Reprod Fertil 1990;43:230-1.

[30] Driancourt MA, Avdi M. Effect of the physiological stage of the ewe on the number of follicles ovulating following hCG injection. Anim Reprod Sci 1993;32:227-36.

[31] Hyttel P, Callesen H, Greve T, Schmidt M. Oocyte maturation and sperm transport in superovulated cattle. Theriogenology 1991;35: 91-108.

[32] Menchaca A, Vilarino M, Crispo M, de Castro T, Rubianes E. New approaches to superovulation and embryo transfer in small ruminants. Reprod Fertil Dev 2010;22:113-8.

[33] Simonetti L, Forcada F, Rivera OE, Carou N, Alberio RH, Abecia JA, et al. Simplified superovulatory treatments in Corriedale ewes. Anim Reprod Sci 2008;104:227-37.

[34] Bartlewski PM, Fuerst KJ, Alexander BD, King WA. Systemic concentrations of endogenous and exogenous FSH in anoestrous ewes superstimulated with Folltropin ${ }^{\circledR}-$ V. Reprod Domest Anim 2009; $44: 353-8$

[35] Candappa IBR, Bartlewski PM. A review of advances in artificial insemination (AI) and embryo transfer (ET) in sheep, with the special reference to hormonal induction of cervical dilation and its implications for controlled animal reproduction and surgical techniques. Open Reprod Sci J 2011;3:162-75.

[36] Oliveira MEF, Cordeiro MF, Ferreira RM, Souza SF, Pieroni JSP, De Souza Rodriges LF, et al. Does supplemental LH changes rate and time to ovulation and embryo yield in Santa Ines ewes treated for superovulation with FSH plus eCG? Ciência Rural, Santa Maria 2012;42:1077-82.

[37] Oliveira MEF, Feliciano MAR, D'Amato CC, Oliveira LG, Bicudo SD, Fonseca JF, et al. Correlations between ovarian follicular blood flow and superovulatory responses in ewes. Anim Reprod Sci 2014;144: $30-7$.

[38] Gordon I. Superovulation. Encyclopedia Anim Sci 2014;1:814-7.

[39] Mayorga I, Mara L, Sanna D, Stelletta C, Morgante M, Casu S, et al. Good quality sheep embryos produced by superovulation treatment without the use of progesterone devices. Theriogenology 2011;75:1661-8.

[40] Chagas e Silva J, Lopes da Costa L, Cidadão R, Robalo Silva J. Plasma progesterone profiles, ovulation rate, donor embryo yield and recipient embryo survival in native Saloia sheep in the fall and spring breeding seasons. Theriogenology 2003;60:521-32.

[41] Evans G, Armstrong DT. Reduction of sperm transport in ewes by superovulation treatment. J Reprod Fertil 1984;70:47-53.

[42] Gonzalez-Bulnes A, Santiago-Moreno J, Cocero MJ, LopezSebastian A. Effects of FSH commercial preparation and follicular status on follicular growth and superovulatory response in Spanish Merino ewes. Theriogenology 2000;54:1055-64.

[43] Murphy BD, Mapletoft RJ, Manns J, Humphrey WD. Variability in gonadotrophin preparations as a factor in the superovulatory response. Theriogenology 1984;21:117-25.

[44] Chupin D, Cognie Y, Combarnous Y, Procureur R, Saumande J. Effect of purified LH and FSH on ovulation in the cow and ewe. In: Roche JF, O'Callaghan D, editors. Follicular growth and ovulation rate in farm animals. The Hague: Martinius Nyhoff; 1987. p. 63-71.

[45] Braileanu GT, Albanese C, Card C, Chedrese PJ. FSH bioactivity in commercial preparations of gonadotropins. Theriogenology 1998; 49:1031-7.

[46] Naqvi SMK, Gulyani R. The effect of gonadotrophin releasing hormone and follicle stimulating hormone in conjunction with pregnant mare serum gonadotrophin on the superovulatory response in crossbred sheep in India. Trop Anim Health Prod 1998;30:369-76.

[47] Scaramuzzi RJ, Adams NR, Baird DT, Campbell BK, Downing JA, Findlay JK, et al. A model for follicle selection and the determination of ovulation rate in the ewe. Reprod Fertil Dev 1993;5:459-78.

[48] Campbell BK, Scaramuzzi RJ, Webb R. Control of follicle development and selection in sheep and cattle. J Reprod Fertil Suppl 1995; 49:335-50. 
[49] McNeilly AS, Baird DT. Episodic secretion of inhibin into ovarian vein during the follicular phase of the oestrous cycle in the ewe. J Endocrinol 1989;122:287-92.

[50] Souza CJH, Campbell BK, Webb R, Baird DT. Secretion of inhibin A and follicular dynamics throughout the estrous cycle in the sheep with and without the Booroola gene (FecB). Endocrinology 1997; 138:5333-40.

[51] Gonzalez-Bulnes A, Santiago-Moreno J, Cocero MJ, Souza CJH, Groome NP, Garcia-Garcia RM, et al. Measurement of inhibin A and follicular status predict the response of ewes to superovulatory FSH treatments. Theriogenology 2002;57:1263-72.

[52] Gonzalez-Bulnes A, Garcia-Garcia RM, Carrizosa JA, Urrutia B, Souza CJH, Cocero MJ, et al. Plasma inhibin A determination at start of superovulatory FSH treatments is predictive for embryo outcome in goats. Domest Anim Endocrinol 2004;26:259-66.

[53] Campbell BK, Picton HM, McNeilly AS, Baird DT. Effect of FSH on ovarian inhibin secretion in anoestrous ewes. J Reprod Fertil 1991; 91:501-9.

[54] Campbell BK, McNeilly AS. Follicular dominance and oocyte maturation. Zygote 1996;4:327-34.

[55] Fuerst KJ, Bartlewski PM, King WA. Relationship between circulating concentrations of ovarian steroids and the superovulatory responses in anestrous ewes following a multiple-dose pFSH regimen. Small Rumin Res 2009;82:144-8.

[56] Moor RM, Osborn JC, Crosby IM. Gonadotrophin-induced abnormalities in sheep oocytes after superovulation. J Reprod Fertil 1985;74:167-72.

[57] Soumano K, Price CA. Ovarian follicular steroidogenic acute regulatory protein, low-density lipoprotein receptor, and cytochrome P450 side-chain cleavage messenger ribonucleic acids in cattle undergoing superovulation. Biol Reprod 1997;56:516-22.

[58] Veiga-Lopez A, Gonzalez-Bulnes A, Tresguerres JAF, Dominguez V, Ariznavarreta C, Cocero MJ. Causes, characteristics and consequences of anovulatory follicles in superovulated sheep. Domest Anim Endocrinol 2006;30:76-87.

[59] Cognie Y, Pelletier J. Preovulatory LH release and ovulation in dry and lactating ewes after progestagen and PMSG treatment during the season anoestrum. Ann Biol Anim Biochim Biophys 1976;16: 529-36.

[60] Quirke JF, Hanrahan JP, Gosling JP. Duration of oestrus, ovulation rate, time of ovulation, and plasma $\mathrm{LH}$, total oestrogen and progesterone in Galway adult ewes and ewe lambs. J Reprod Fertil 1981;61:265-72.

[61] Robinson TJ, Scaramuzzi RJ, Smith CA. The time of mating and of LH release and subsequent fertility of anestrous Border Leicester $\mathrm{x}$ Merino ewes treated with progestagen and pregnant mare serum gonadotrophin. J Reprod Fertil 1987;17:471-83.

[62] Pugh PA, Fukui Y, Tervit HR, Thompson JG. Developmental ability of in vitro matured sheep oocytes collected during the nonbreeding season and fertilized in vitro with frozen ram semen. Theriogenology 1991;36:771-8.

[63] Bartlewski PM, Beard AP, Chapman CL, Nelson ML, Palmer B, Aravindakshan J, et al. Ovarian responses in GnRH-treated anoestrous ewes: follicular and endocrine correlates with luteal outcome. Reprod Fertil Dev 2001;13:133-42.

[64] Lopez-Alonso C, Encinas T, Veiga-Lopez A, Garcia-Garcia RM, Cocer MJ, Ros JM, et al. Follicular growth, endocrine response and embryo yields in sheep superovulated with FSH and after pretreatment with a single short-acting dose of GnRH antagonist. Theriogenology 2005;64:1833-43.

[65] Veiga-Lopez A, Encinas T, McNeilly AS, Gonzalez-Bulnes A. Timing of preovulatory LH surge and ovulation in superovulated sheep are affected by follicular status at start of the FSH treatment. Reprod Domest Anim 2008;43:92-8.

[66] D'Occhio MJ, Jillella D, Lindsey BR. Factors that influence follicle recruitment, growth and ovulation during ovarian superstimulation in heifers: opportunities to increase ovulation rate and embryo recovery by delaying the exposure of follicles to $\mathrm{LH}$. Theriogenology 1999;51:9-35.

[67] Walker SK, Smith DH, Frensham A, Ashman RJ, Seamark RF. The use of synthetic gonadotropic releasing hormone treatment in the collection of sheep embryos. Theriogenology 1989;31:741-52.

[68] Menchaca A, Vilarino M, Pinczak A, Kmaid S, Saldana JM. Progesterone treatment, FSH plus eCG, GnRH administration and Day 0 protocol for MOET programs in sheep. Theriogenology 2009;72: 477-83.

[69] Noel B, Bister JL, Pierquin B, Paquay R. Effects of FGA and PMSG on follicular growth and LH secretion in Suffolk ewes. Theriogenology 1994;41:719-27.
[70] Leyva V, Buckrell BC, Walton JS. Regulation of follicular activity and ovulation in ewes by exogenous progestagen. Theriogenology 1998;50:395-416.

[71] Rubianes E, de Castro T, Carvajal B. Effect of high progesterone levels during the growing phase of the dominant follicle of wave 1 in ultrasonographically monitored ewes. Can J Anim Sci 1996;76: 473-5.

[72] Salehi R, Kohram H, Towhidi A, Kermani Moakhar H, Honarvar M. Follicular development and ovulation rate following different superovulatory treatments in Chall ewes. Small Ruminant Res 2010;93:213-7.

[73] Grazul-Bilska AT, Kirsch JD, Bilski JJ, Kraft KC, Windorski EJ, Luther JS, et al. Superovulation in sheep: number and weight of the corpora lutea and serum progesterone. Sheep Goat Res J 2007;22: 26-31.

[74] Barrett DMW, Bartlewski PM, Duggavathi R, Davies KL, Rawlings NC. Suppression of follicle wave emergence in cyclic ewes by supraphysiological concentrations of estradiol-17 $\beta$ and induction with a physiological dose of exogenous ovine folliclestimulating hormone. Biol Reprod 2006;75:633-41.

[75] Moore LG, Ng Chie W, Hudson NL, McNatty KP. Isoforms and halflife of FSH from sheep with different reproductive states. J Endocrinol 2000;165:185-92.

[76] Baby TE, Bartlewski PM. Progesterone as the driving regulatory force behind serum follicle-stimulating hormone (FSH) concentrations and antral follicular growth in cyclic ewes. Reprod Fertil Dev 2011;23:303-10.

[77] Andersen CY, Westergaard LG, van Wely M. FSH isoform composition of commercial gonadotrophin preparations: a neglected aspect? Reprod Biomed Online 2004;9:231-6.

[78] West CR, Carlson NE, Lee JS, Mc Neilly AS, Sharma TP, Ye W, et al. Acidic mix of FSH isoforms are better facilitators of ovarian follicular maturation and E2 production than the less acidic. Endocrinology 2002;143:107-16.

[79] Al-Azemi M, Killick SR, Duffy S, Pye C, Refaat B, Hill N, et al. Multimarker assessment of ovarian reserve predicts oocyte yield after ovulation induction. Hum Reprod 2011;26:414-22.

[80] Riggs R, Kimble T, Oehninger S, Bocca S, Zhao Y, Leader B, et al. Anti-Mullerian hormone serum levels predict response to controlled ovarian hyperstimulation but not embryo quality or pregnancy outcome in oocyte donation. Fertil Steril 2011;95: 410-2.

[81] Rico C, Fabre S, Medigue C, di Clemente N, Clément F, Bontoux M, et al. Anti-Mullerian hormone is an endocrine marker of ovarian gonadotropin-responsive follicles and can help to predict superovulatory responses in the cow. Biol Reprod 2009;80:50-9.

[82] Monniaux D, Barbey S, Rico C, Fabre S, Gallard Y, Larroque H. AntiMüllerian hormone: a predictive marker of embryo production in cattle. Reprod Fertil Dev 2010;22:1083-91.

[83] Monniaux D, Baril G, Laine AL, Jarrier P, Poulin N, Cognie J, et al. Anti-Müllerian hormone as a predictive endocrine marker for embryo production in the goat. Reproduction 2011;142:845-54.

[84] Cate RL, Mattaliano RJ, Hession C, Tizard R, Farber NM, Cheung A, et al. Isolation of the bovine and human genes for Mullerian inhibiting substance and expression of the human gene in animal cells. Cell 1986;45:685-98.

[85] Vigier B, Picard JY, Tran D, Legeai L, Josso N. Production of antiMüllerian hormone: another homology between Sertoli and granulosa cells. Endocrinology 1984;114:1315-20.

[86] Lahoz B, Alabart JL, Cocero MJ, Monniaux D, Echegoyen E, Sánchez P, et al. Anti-Müllerian hormone concentration in sheep and its dependence of age and independence of BMP15 genotype: an endocrine predictor to select the best donors for embryo biotechnologies. Theriogenology 2014;81:347-57.

[87] Vernuft A, Schwerhoff M, Viergutz T, Diedrich M, Kuwer A. AntiMüllerian hormone (AMH) levels in plasma of Holstein-Friesian heifers as a predictive parameter for ovum pick-up and embryo production outcomes. J Reprod Dev 2015;61:74-9.

[88] Brebion P, Cognie Y. Increased superovulation in the ewe following 14 days of GnRH agonist pre-treatment. Proceedings of the $5^{\text {th }}$ Meeting on European Embryo Transfer Association, (EETA'89), Lyon, France; 1989. p. 106-106.

[89] England BG, Webb R, Dahmer MK. Follicular steroidogenesis and gonadotrophin binding to ovine follicles during the oestrous cycle. Endocrinology 1981;109:881-7.

[90] Evans ACO, Flynn JD, Duffy P, Knight PG, Boland MP. Effects of ovarian ablation on FSH, estradiol and inhibin A concentrations on growth of other follicles in sheep. Reproduction 2002;123: 59-66. 
[91] Monniaux D, Pisselet C. Control of proliferation and differentiation of ovine granulosa cells by insulin-like growth factor-1 and follicle-stimulating hormone in vitro. Biol Reprod 1992;46: 109-19.

[92] Armstrong DG, Hogg CO, Campbell BK, Webb R. Insulin-like growth factor (IGF)-binding protein production by primary cultures of ovine granulose and theca cells. The effects of IGF-1 gonadotrophin, and follicle size. Biol Reprod 1996;55:1163-71.

[93] Adams GP. Comparative patterns of follicle development and selection in ruminants. J Reprod Fertil Suppl 1999;54:17-32.

[94] Gonzalez-Bulnes A, Garcia-Garcia RM, Santiago-Moreno J, Dominguez V, Lopez-Sebastian A, Cocero MJ. Reproductive season affects inhibitory effects from large follicles on the response to superovulatory FSH treatments in ewes. Theriogenology 2003;60: 281-8.

[95] Rubianes E, Ibarra D, Ungerfeld R, Carbajal B, de Castro T. Superovulatory response in anestrous ewes is affected by the presence of a large follicle. Theriogenology 1995;43:465-72.

[96] Rubianes E, Ungerfeld R, Vinoles C, Rivero A, Adams GP. Ovarian response to gonadtropin treatment initiated relative to wave emergence in ultrasonographically monitored ewes. Theriogenology 1997;47:1479-88.

[97] Veiga-Lopez A, Cocero MJ, Dominguez V, McNeilly AS, GonzalezBulnes A. Follicular wave status at the beginning of FSH treatment modifies reproductive features in superovulated sheep. Reprod Biol 2006;6:243-64

[98] Duggavathi R, Bartlewski PM, Barrett DMW, Gratton C, Bagu ET, Rawlings NC. Patterns of antral follicular wave dynamics and accompanying endocrine changes in cyclic and seasonally anestrous ewes treated with exogenous ovine FSH during the interwave interval. Biol Reprod 2004;70:821-7.
[99] Duggavathi R, Bartlewski PM, Agg E, Flint S, Barrett DMW, Rawlings NC. The effect of the manipulation of FSH-peak characteristics on follicular wave dynamics in sheep: does an ovarianindependent exogenous rhythm in FSH secretion exist? Biol Reprod 2005;72:1466-74.

[100] Bartlewski PM, Baby TE, Giffin JL. Reproductive cycles in sheep. Anim Reprod Sci 2011;124:259-68.

[101] Gonzalez-Bulnes A, Berlinguer F, Cocero MJ, Garcia-Garcia RM, Leoni $G$, Naitana $S$, et al. Induction of the presence of corpus luteum during superovulatory treatments enhances in vivo and in vitro blastocysts output in sheep. Theriogenology 2005;64: 1392-403.

[102] Bartlewski PM, Beard AP, Rawlings NC. Ultrasonographic study of the effects of the corpus luteum on antral follicular development in unilaterally ovulating Western white-faced ewes. Anim Reprod Sci 2001;65:231-44.

[103] Borman SM, Chaffin CL, Schwinof KM, Stouffer RL, ZelinskiWooten MB. Progesterone promotes oocyte maturation, but not ovulation, in nonhuman primate follicles without a gonadotropin surge. Biol Reprod 2004;71:366-73.

[104] Honnens A, Niemann H, Paul V, Meyer HH, Bollwein H. Doppler sonography of the uterine arteries during a superovulatory regime in cattle: uterine blood flow in superovulated cattle. Theriogenology 2008;70:859-67.

[105] Honnens A, Niemann H, Herzog K, Paul V, Meyer HH, Bollwein H. Relationships between ovarian blood flow and ovarian response to eCG-treatment of dairy cows. Anim Reprod Sci 2009;113:1-10.

[106] Witt MC, Bollwein H, Probst J, Baackmann C, Squires EL, Sieme H. Doppler sonography of the uterine and ovarian arteries during a superovulatory program in horses. Theriogenology 2012;77: 1406-14. 